\title{
Synthesis, Spectral Characterization and X - Ray Diffraction studies of some Pd(II) Complexes with Schiff bases
}

\author{
Julekha A. Shaikh \\ Department of Chemistry, Maharashtra College of Arts, Science and Commerce, \\ 246 - A, JBB Marg, Mumbai 400 008, India \\ E-mail address: shaikh.julekha@gmail.com
}

\begin{abstract}
The synthesis, spectroscopic and X - Ray Diffraction studies of some Pd(II) complexes with bidentate Schiff bases are reported here. These Schiff bases were derived by condensing aldehydes like 2-hydroxy-1-naphthaldehyde, 5-chloro salicyladehyde with amines like 4-nitro aniline, 4-methyl aniline and 4-methoxy aniline. The complexes were characterized on the basis of elemental analysis, molar conductivity, spectral (IR, ${ }^{1} \mathrm{H}$ and electronic) as well as thermal analysis. All the Pd (II) complexes exhibit square planar geometry with 1:2 (metal : ligand) stoichiometry. The X- ray diffraction studies suggest monoclinic crystal system for these complexes.
\end{abstract}

Keywords: Pd(II) complexes; Schiff bases; Structural analysis; X- ray diffraction studies

\section{INTRODUCTION}

Progress in the field of Coordination chemistry has received considerable significance because of its importance in chemical industry and life itself.

Schiff bases contain azomethine $(>\mathrm{C}=\mathrm{N})$ group as functional group and hence act as an effective ligand.

Transition metal complexes of Schiff bases have witnessed a great deal of interest in the recent years because of their chemical, pharmacological ${ }^{1,2}$ and analytical applications ${ }^{3}$. In addition the presence of nitrogen and oxygen donor atoms in the complexes act as stereospecific catalyst for many reactions like oxidation ${ }^{4}$, reduction ${ }^{5}$, hydrolysis and possess antibacterial activity ${ }^{6}$.

In this paper, the synthesis, characterization and crystal lattice parameters of some $\mathrm{Pd}$ (II) complexes with bidentate Schiff base ligands are reported. 


\section{MATERIALS AND METHODS}

\section{1. Chemicals}

All chemicals used were of A. R. grade purchased from S. D. Fine chemicals (Mumbai) and used without further purification. Distilled solvents were used throughout the experiments.

\section{2. Synthesis of Schiff bases}

The Schiff base was synthesized by condensing ethanolic solution of $0.01 \mathrm{~mol}$ of aldehyde with $0.01 \mathrm{~mol}$ of amine in 1:1 stoichiometric ratio and refluxed for 3-4 hours. The solution was then reduced to $14^{\text {th }}$ of its original volume and poured in ice cold water. The solid precipitated was filtered off, washed with methanol and then recrystallized from ethanol. The purity of ligands was checked by thin layer chromatography and elemental analysis. The yield of the ligands was about $80-95 \%$.

$\mathrm{L}^{1} \mathrm{H}=$ 2-hydroxy -1-naphthaldehyde (1.722 g) and 4-nitro aniline (1.382 g).

$\mathrm{L}^{2} \mathrm{H}=$ 2-hydroxy -1-naphthaldehyde (1.722 g) and 4-methyl aniline (1.072 g).

$\mathrm{L}^{3} \mathrm{H}=5$ - chloro salicyladehyde (1.567 g) and 4-methoxy aniline (1.230 g).

\section{3. Synthesis of the Pd complexes}

All the complexes were prepared by adding stoichiometric amount of ligands to metal chlorides in a 2:1 mole. To an ethanolic solution of $0.002 \mathrm{~mol}$ of ligand, ethanolic solution of $\mathrm{PdCl}_{2}(0.001 \mathrm{~mol})$ was added. The reaction mixture was refluxed for about 4-5 hours and the $\mathrm{pH}$ adjusted to optimum level. The complexes which precipitated were filtered off, washed with cold methanol and recrystallized from ethanol. The products were finally dried in vacuum over fused Calcium Chloride.

\section{4. Experimental Analysis}

Metal content was determined in the laboratory by the reported methods ${ }^{7}$. C, $\mathrm{H}$ and $\mathrm{N}$ analyses were performed at the IIT Mumbai. The infra-red spectra of the ligands and of their metal complexes were recorded in $\mathrm{KBr}$ pellets in the $4000-400 \mathrm{~cm}^{-1}$ region using a FTIR spectrum One supplied by Perkin Elmer instrument. The electronic Spectra were recorded in DMSO solution using a UV-visible 2100 Spectrophotometer supplied by M/s Perkin Elmer lambda 25. The ${ }^{1} \mathrm{H}$ NMR spectra were recorded in DMSO using a Bruker Advance $300 \mathrm{MHz}$ spectrometer. TGA analysis was carried out using a Pyris Diamond TGA supplied by Perkin Elmer instruments. The X-ray analysis was carried out at TIFR Mumbai.

\section{RESULTS AND DISCUSSION}

All the metal complexes are crystalline solids and decompose at high temperature. The complexes are insoluble in water, ethanol, methanol, chloroform, carbon tetrachloride etc. but soluble in DMF and DMSO. The elemental analysis show 1:2 (metal : ligand) stoichiometry for all the complexes. The analytical data along with some physical properties of the ligand and metal complexes are reported in Table 1 . The molar conductivities of $1 \times 10^{-3} \mathrm{~S} \mathrm{~cm}^{2} \mathrm{~mol}^{-1}$ solutions of the complexes in DMSO indicate their non-electrolytic nature ${ }^{8}$. 
Table 1. Physical and Analytical Data of the Ligand and Metal Complexes.

\begin{tabular}{|c|c|c|c|c|c|c|c|c|}
\hline \multirow{2}{*}{ Ligand/Complex } & \multirow{2}{*}{$\begin{array}{l}\text { Mol. Wt. } \\
\text { (Colour) }\end{array}$} & \multirow{2}{*}{$\begin{array}{l}\text { M. P. } \\
\left({ }^{\circ} \mathrm{C}\right)\end{array}$} & \multirow{2}{*}{$\begin{array}{c}\hat{M}_{\mathrm{M}} \\
\left(\mathrm{S} \mathrm{cm}^{2}\right. \\
\left.\mathrm{mole}^{-1}\right)\end{array}$} & \multicolumn{5}{|c|}{$\begin{array}{c}\text { Elemental Analysis } \\
\% \text { Found } \\
\% \text { (Calculated) } \\
\end{array}$} \\
\hline & & & & $\mathbf{C}$ & $\mathbf{H}$ & $\mathbf{N}$ & Cl & $\mathbf{M}$ \\
\hline $\begin{array}{c}\mathrm{C}_{17} \mathrm{H}_{12} \mathrm{O}_{3} \mathrm{~N}_{2} \\
\mathrm{~L}^{1} \mathrm{H}\end{array}$ & $\begin{array}{c}292.00 \\
\text { (Orange red) }\end{array}$ & 225 & -- & $\begin{array}{c}69.82 \\
(69.86)\end{array}$ & $\begin{array}{c}3.89 \\
(4.10)\end{array}$ & $\begin{array}{c}9.23 \\
(9.58)\end{array}$ & -- & -- \\
\hline $\begin{array}{c}\mathrm{Pd}\left(\mathrm{C}_{34} \mathrm{H}_{22} \mathrm{O}_{6} \mathrm{~N}_{4}\right) \\
\operatorname{Pd}\left(\mathrm{L}^{1}\right)_{2}\end{array}$ & $\begin{array}{c}688.42 \\
\text { (Yellow) }\end{array}$ & $>300$ & 16.10 & $\begin{array}{c}58.42 \\
(59.26)\end{array}$ & $\begin{array}{c}3.52 \\
(3.19)\end{array}$ & $\begin{array}{c}8.20 \\
(8.13)\end{array}$ & -- & $\begin{array}{r}15.22 \\
(15.45)\end{array}$ \\
\hline $\begin{array}{c}\mathrm{C}_{18} \mathrm{H}_{15} \mathrm{ON} \\
\mathrm{L}^{2} \mathrm{H}\end{array}$ & $\begin{array}{c}261.00 \\
\text { (Yellow) }\end{array}$ & 130 & -- & $\begin{array}{c}82.66 \\
(82.75)\end{array}$ & $\begin{array}{c}5.47 \\
(5.74)\end{array}$ & $\begin{array}{c}5.23 \\
(5.36)\end{array}$ & $\begin{array}{l}-- \\
--\end{array}$ & $\begin{array}{l}-- \\
--\end{array}$ \\
\hline $\begin{array}{c}\mathrm{Pd}\left(\mathrm{C}_{36} \mathrm{H}_{28} \mathrm{O}_{2} \mathrm{~N}_{2}\right) \\
\operatorname{Pd}\left(\mathrm{L}^{2}\right)_{2}\end{array}$ & $\begin{array}{l}626.42 \\
\text { (Green) }\end{array}$ & 240 & 16.90 & $\begin{array}{c}68.72 \\
(68.96)\end{array}$ & $\begin{array}{c}4.52 \\
(4.47)\end{array}$ & $\begin{array}{c}4.20 \\
(4.47)\end{array}$ & $\begin{array}{l}-- \\
--\end{array}$ & $\begin{array}{r}16.77 \\
(16.98)\end{array}$ \\
\hline $\begin{array}{c}\mathrm{C}_{14} \mathrm{H}_{12} \mathrm{O}_{2} \mathrm{NCl} \\
\mathrm{L}^{3} \mathrm{H}\end{array}$ & $\begin{array}{l}261.5 \\
\text { (Green } \\
\text { Yellow) }\end{array}$ & 137 & -- & $\begin{array}{l}62.45 \\
(64.24)\end{array}$ & $\begin{array}{c}4.47 \\
(4.59)\end{array}$ & $\begin{array}{c}5.23 \\
(5.35)\end{array}$ & $\begin{array}{c}13.36 \\
(13.57)\end{array}$ & $\begin{array}{l}-- \\
--\end{array}$ \\
\hline $\begin{array}{c}\mathrm{Pd}\left(\mathrm{C}_{28} \mathrm{H}_{22} \mathrm{O}_{4} \mathrm{~N}_{2} \mathrm{Cl}_{2}\right) \\
\mathrm{Pd}\left(\mathrm{L}^{3}\right)_{2}\end{array}$ & $\begin{array}{c}627.42 \\
\text { (Brown) }\end{array}$ & 255 & 18.30 & $\begin{array}{c}53.42 \\
(53.55)\end{array}$ & $\begin{array}{c}3.52 \\
(3.50)\end{array}$ & $\begin{array}{c}4.20 \\
(4.46)\end{array}$ & $\begin{array}{c}11.21 \\
(11.36)\end{array}$ & $\begin{array}{r}16.60 \\
(16.96)\end{array}$ \\
\hline
\end{tabular}

\section{1. IR Spectra}

The infrared spectra of the free ligands were compared with those of their $\mathrm{Pd}(\mathrm{II})$ complexes to determine the bonding mode of the ligands to the metal in the complexes. The spectra of the ligands shows strong and broad absorption band in the region $3450-3050 \mathrm{~cm}^{-1}$, which is assigned to hydrogen bonded $v_{(0-\mathrm{H})}$ stretching vibration ${ }^{9}$. This band is missing in the complexes indicating the absence of water molecule which is further confirmed by TGA analysis. The phenolic oxygen, after the loss of $\mathrm{OH}$ proton gets coordinated to the metal is further supported by the shift in the stretching frequency of the $\boldsymbol{v}_{(\mathrm{C}-\mathrm{O})}$ to lower wave numbers by $20-30 \mathrm{~cm}^{-1}$ from its position in the free ligands $1^{10,11}$.

The coordination of azomethine nitrogen is confirmed by the presence of bands in the $1625-1600 \mathrm{~cm}^{-1}$ region in the ligand which underwent a shift to a lower frequency after complexation $^{12}$. All complexes show extra bands in the $580-520 \mathrm{~cm}^{-1}$ and $485-470 \mathrm{~cm}^{-1}$ region assigned to $\boldsymbol{v}_{(\mathrm{M}-\mathrm{N})}$ and $\boldsymbol{v}_{(\mathrm{M}-\mathrm{O})}$ stretching vibrations. This data is in good agreement with literature value $\mathrm{e}^{13,14}$.

Thus these Schiff bases behave as bidentate ligand coordinating through the deprotonated phenolic oxygen and azomethine nitrogen. Selected IR bands for the ligands and their metal complexes along with their tentative assignment are given in Table 2. 


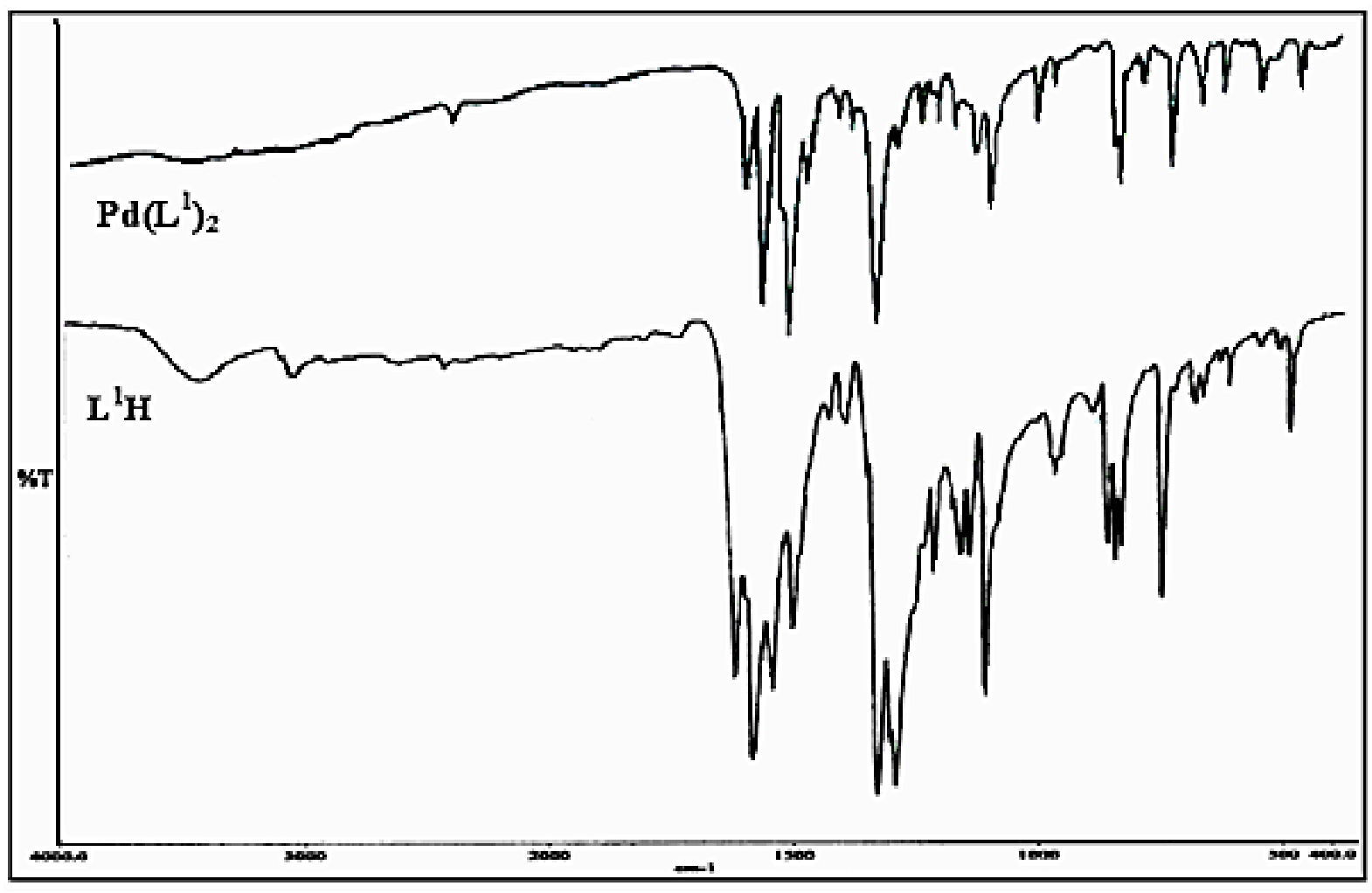

Figure 1. Infrared absorption Spectra of $\mathrm{L}^{1} \mathrm{H}$ and $\mathrm{Pd}\left(\mathrm{L}^{1}\right)_{2}$.

\section{2. ${ }^{1} \mathrm{H}$ NMR Spectra}

The ${ }^{1} \mathrm{H}$ NMR spectra of the ligands and Pd(II) complexes were recorded in DMSO solvent and the assignments are detailed in Table 2 .

Table 2. IR Spectral data $\left(\mathrm{cm}^{-1}\right)$ and ${ }^{1} \mathrm{H}$ NMR spectra of Ligand and Metal Complexes.

\begin{tabular}{|c|c|c|c|c|c|c|c|c|}
\hline \multirow[t]{2}{*}{ Ligand/complexes } & \multicolumn{5}{|c|}{ IR Spectral data $\left(\mathrm{cm}^{-1}\right)$} & \multicolumn{3}{|c|}{$\begin{array}{c}{ }^{1} \text { H NMR } \\
\text { Chemical Shift }(\delta \text { ppm) }\end{array}$} \\
\hline & $v_{(0-H)}$ & $\mathbf{v}_{(\mathrm{C}=\mathrm{N})}$ & $v_{(C-O)}$ & $\mathbf{v}_{(\mathbf{M}-\mathbf{N})}$ & $v_{(\mathbf{M}-\mathbf{O})}$ & Aromatic & $\mathbf{C H}=\mathbf{N}$ & $\mathbf{O H}$ \\
\hline $\mathrm{L}^{1} \mathrm{H}$ & 3434 & 1621 & 1398 & --- & --- & $6.95-8.50$ & 9.64 & 14.21 \\
\hline $\operatorname{Pd}\left(L^{1}\right)_{2}$ & ---- & 1602 & 1278 & 517 & 485 & $6.60-8.83$ & 10.20 & --- \\
\hline $\mathrm{L}^{2} \mathrm{H}$ & 3050 & 1620 & 1290 & ---- & --- & $6.52-8.40$ & 8.95 & 14.11 \\
\hline $\operatorname{Pd}\left(\mathrm{L}^{2}\right)_{2}$ & ---- & 1600 & 1259 & 580 & 470 & $6.46-8.73$ & 9.40 & --- \\
\hline $\mathrm{L}^{3} \mathrm{H}$ & 3436 & 1624 & 1485 & --- & --- & $7.00-8.60$ & 9.20 & 14.70 \\
\hline $\operatorname{Pd}\left(L^{3}\right)_{2}$ & --- & 1609 & 1464 & 544 & 472 & $6.70-8.62$ & 9.46 & --- \\
\hline
\end{tabular}


The $\mathrm{OH}$ protons that appeared in the region 14.11-14.70 ppm disappeared in the complexes confirming the deprotonation of the hydroxyl proton due to coordination of oxygen to the central metal atom ${ }^{15}$. The signals of azomethine appeared to be deshielded as they showed a downfield shift compared to the respective ligands indicating coordination through azomethine nitrogen atom ${ }^{16}$. The multiplets in the region $6.46-8.83 \mathrm{ppm}$ were assigned to aromatic ring protons.

\section{3. Electronic Spectra}

The electronic spectrum of Pd(II) complex display bands at $22600-23419 \mathrm{~cm}^{-1}, 27777$ $28500 \mathrm{~cm}^{-1}$ and 29411-30300 $\mathrm{cm}^{-1}$ which may be assigned to ${ }^{1} \mathrm{~A}_{1 \mathrm{~g}} \rightarrow{ }^{1} \mathrm{~B}_{1 \mathrm{~g}},{ }^{1} \mathrm{~A}_{1 \mathrm{~g}} \rightarrow{ }^{1} \mathrm{E}_{1 \mathrm{~g}}$ and ${ }^{1} \mathrm{~A}_{1 \mathrm{~g}} \rightarrow{ }^{1} \mathrm{~A}_{2 \mathrm{~g}}$ transitions respectively ${ }^{17}$. These transitions correspond to the three $\mathrm{d}-\mathrm{d}$ spin forbidden transitions from the lower lying $d$ levels to the empty $d_{x 2-y 2}$ orbitals, the ground state ${ }^{1} \mathrm{~A}_{1 \mathrm{~g}}$ and excited states corresponding to the transitions are ${ }^{1} \mathrm{~A}_{2 \mathrm{~g}},{ }^{1} \mathrm{~B}_{1 \mathrm{~g}}$ and ${ }^{1} \mathrm{E}_{\mathrm{g}}$ in order of increasing energy. It is in fairly good agreement with the transitions suggested for $\mathrm{Pd}(\mathrm{II})$ complexes having square planar environment of ligands ${ }^{18,19}$. This is further supported by diamagnetic behaviour of $\mathrm{Pd}(\mathrm{II})$ from the magnetic susceptibility measurements.

\section{4. Thermal analysis}

The thermal decompositions of the complexes were studied using the TGA technique in air within the range $30-1000^{\circ} \mathrm{C}$ at $10{ }^{\circ} \mathrm{C} / \mathrm{min}$. The thermograms of $\mathrm{Pd}\left(\mathrm{L}^{1}\right)_{2}, \mathrm{Pd}\left(\mathrm{L}^{2}\right)_{2}$ and $\operatorname{Pd}\left(\mathrm{L}^{3}\right)_{2}$ do not show any significant loss between R.T to $120^{\circ} \mathrm{C}$ indicating absence of water molecules as it is thermally stable upto $200^{\circ} \mathrm{C}$. It was observed that for all the complexes decomposition begins around $250-300{ }^{\circ} \mathrm{C}$ and are completely decomposed around 550-650 ${ }^{\circ} \mathrm{C}$. After decomposition metal oxide remain as a residue $\mathrm{e}^{20-24}$. The percentage loss at decomposition temperature was in agreement with the calculated values.

\section{5. XRD Analysis}

In X-ray diffractogram of the complexes, major refluxes were recorded in the range $5^{\circ}$ to $60^{\circ} 2 \theta$ value. The major refluxes were measured and corresponding $d$-values were obtained using Bragg's equation. The independent indexing of major refluxes was carried out using least square method. The miller indices $h, k, l$ were calculated and refined by using Back - cal program on computer. The complexes were successfully indexed to monoclinic system with $Z=16$ for all the complexes ${ }^{21}$. The lattice parameters are summarized in Table 3 . The correctness of $d$-values was confirmed by comparing the observed density with that calculated from the X-ray diffractogram. 
Table 3. Crystal Lattice Parameters of Metal Complexes.

\begin{tabular}{|c|c|c|c|c|c|c|c|c|c|}
\hline Complex & $\mathrm{a}\left(\mathrm{A}^{\mathrm{o}}\right)$ & $\mathrm{b}\left(\mathrm{A}^{\mathrm{o}}\right)$ & $\mathrm{c}\left(\mathrm{A}^{\mathrm{o}}\right)$ & $\alpha^{\mathrm{o}}$ & $\beta^{\mathrm{o}}$ & $\gamma^{\mathrm{o}}$ & $\begin{array}{c}\mathrm{D}_{\text {obs }} \\
\left(\mathrm{g} / \mathrm{cm}^{3}\right)\end{array}$ & $\begin{array}{c}\mathrm{D}_{\text {cal }} \\
\left(\mathrm{g} / \mathrm{cm}^{3}\right)\end{array}$ & $\begin{array}{c}\text { Vol. } \\
\left(\mathrm{A}^{3}\right)\end{array}$ \\
\hline$\left[\mathrm{Pd}\left(\mathrm{L}^{1}\right)_{2}\right]$ & $\begin{array}{c}13.4778 \\
\pm 0.013\end{array}$ & $\begin{array}{c}13.9495 \\
\pm 0.0242\end{array}$ & $\begin{array}{c}16.8129 \\
\pm 0.0235\end{array}$ & 90 & 87.32 & 90 & 1.4205 & 1.3985 & 3009.77 \\
\hline$\left[\mathrm{Pd}\left(\mathrm{L}^{2}\right)_{2}\right]$ & $\begin{array}{c}14.8131 \\
\pm 0.0200\end{array}$ & $\begin{array}{c}18.6662 \\
\pm 0.0185\end{array}$ & $\begin{array}{c}21.4753 \\
\pm 0.0524\end{array}$ & 90 & 86.83 & 90 & 1.7224 & 1.5180 & 2753.02 \\
\hline$\left[\mathrm{Pd}\left(\mathrm{L}^{3}\right)_{2}\right]$ & $\begin{array}{c}21.6319 \\
\pm 0.0331\end{array}$ & $\begin{array}{c}20.5460 \\
\pm 0.1070\end{array}$ & $\begin{array}{c}36.1623 \\
\pm 0.2845\end{array}$ & 90 & 72.21 & 90 & 1.7861 & 1.7802 & 15882.09 \\
\hline
\end{tabular}

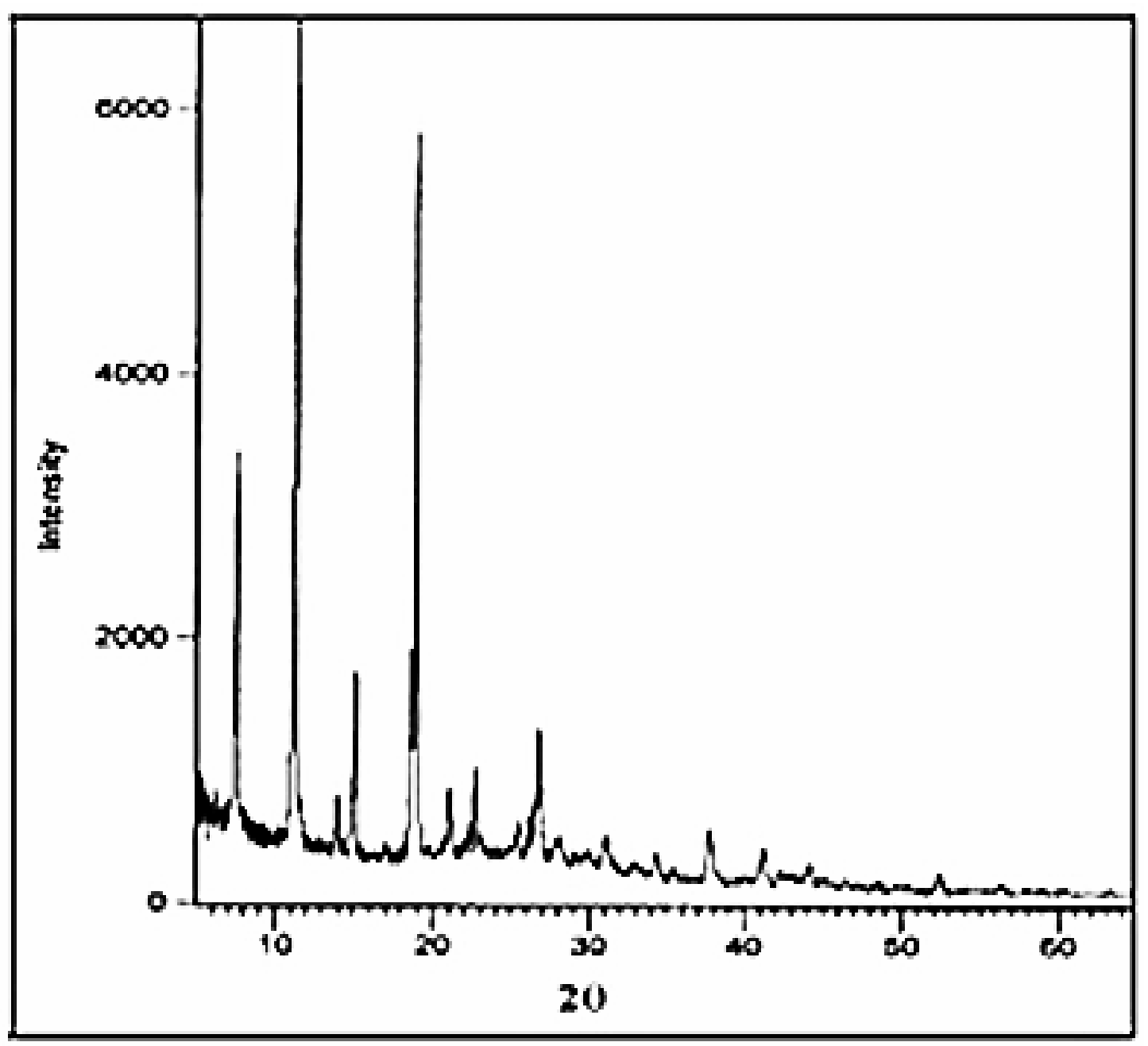

Figure. 2. $\mathrm{X}$ - Ray Diffractogram of $\mathrm{Pd}\left(\mathrm{L}^{1}\right)_{2}$. 


\section{CONCLUSIONS}

The Schiff base and their Pd(II) complexes were characterized by elemental analysis, conductance measurements, IR, ${ }^{1} \mathrm{H}$ NMR, uv-vis spectra, thermal and XRD studies. On the basis of above data these Schiff bases appear to behave as bidentate ligand coordinating through the deprotonated phenolic oxygen and azomethine nitrogen in $\mathrm{Pd}(\mathrm{II})$ complexes and exhibit square planar structure.

The proposed structures are:
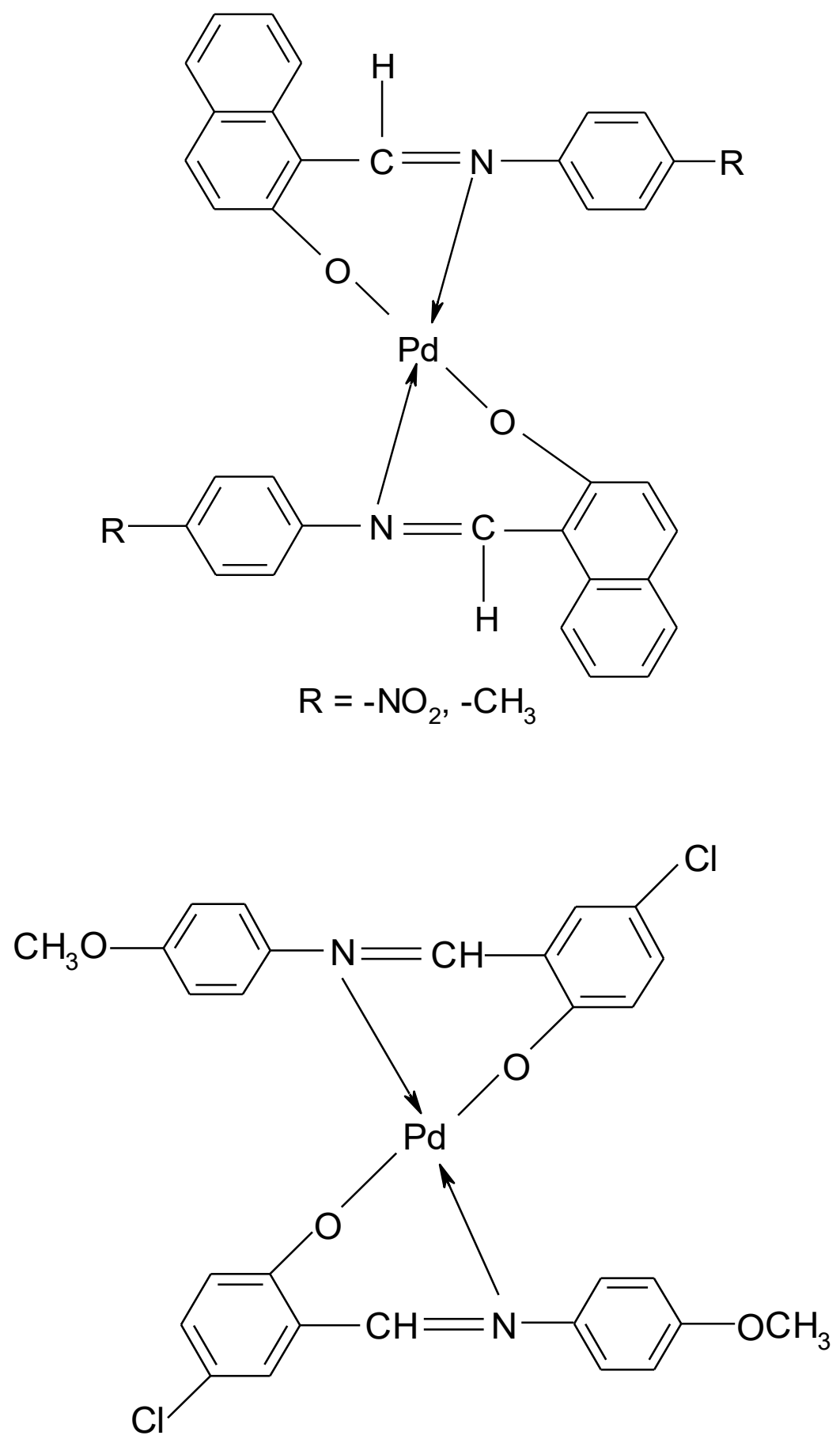


\section{Acknowledgement}

The author is thankful to Dr. B. H. Mehta, Ex-Head, Department of Chemistry, University of Mumbai for providing the XRD data using Back Cal program by computational method.

\section{References}

[1] V. M. Leovac, V. Divakovic, D. Petrovic, G. Argay, A. Kalman, Polyhedron 2 (1983) 1307.

[2] S. Padhye, G. B. Kauffman, Coord. Chem Reviews 63 (1985) 127.

[3] R. B. Singh, H. Ishii, Critical Reviews in Analytical Chemistry 22 (1991) 381.

[4] R. I. Kureshy, N. H. Khan, S. H. R. Abdi, S. T. Patel, P. Iyer, J. Mol Catalysis 150 (1999) 175.

[5] Y. Aoyama, J.T Kujisawa, T. Walanawe, A. Toi, H. Ogashi, J. Am. Chem. Soc. 108 (1986) 943.

[6] T. Daniel. Thangadurai, K. Natarajan, Indian J. Chem. 41A (2002) 741.

[7] A. I. Vogel, Vogel's Text Book of Quantitative Inorganic Analysis, $5^{\text {th }}$ edn, ELBS Longman. (1991) 463.

[8] S. Chandra, U. Kumar, Spectrochemica Acta. 61A (2005) 219.

[9] L. N. Sharda, M. C. Ganorkar, Indian J. Chem. 27A (1988) 617.

[10] B. H. Mehta and J. A. Shaikh, J Indian Chem. Soc. 86 (2009) 624.

[11] A. Cukurovali, Yilmaz, H. Ozmen, M. Ahmedzada, Transition Met Chem. 27 (2002) 171.

[12] V. Chinnusamy, K. Natarajan, Synthesis and Reactivity in Inorganic, Metal-Organic and Nano metal Chemistry 23 (1993) 889.

[13] V. K. Sharma, S. Shrivastava, A. Shrivastava, Bioinorganic Chemistry and Applications. Article ID 68374 (2007) 10 pages.

[14] A. S. El-Tabl, M. I. Ayad, Synthesis and Reactivity in Inorganic, Metal-Organic and Nano metal Chemistry 33 (2003) 369.

[15] P. S. Kalsi, Spectroscopy of Organic Compounds, $5^{\text {th }}$ edn, New Age International (P) Limited Publishers, New Delhi. (2002).

[16] L. K. W. Henri, J. Tagenine, B. M. Gupta, Indian J. Chem. 40A (2001) 999.

[17] S. Dagaonkar, B. H. Mehta, Asian J. Chem. 7 (1995) 611.

[18] S. Chandra, R. Singh, Indian J. Chem. 27A (1988) 417.

[19] M. K. Biyala, N. Fahmi, R. V. Singh, Indian J Chem. 43 (2004) 2536.

[20] B. H. Mehta, D. S. Joishar, Asian J. Chem. 17 (2005) 1041. 
[21] F. M. Norman, K. Lonsdale, International Tables for Crystallography, McGraw Hill Book Co., New York. (1968).

[22] S. D. Dhanavate, D. J. Garole, V. J. Garole, S. R. Tetgure, A. D. Sawant, International Letters of Chemistry, Physics and Astronomy 4 (2014) 20-28.

[23] S. M. S. Shariar, M. Jesmin, M. M. Ali, International Letters of Chemistry, Physics and Astronomy 7 (2014) 53-61.

[24] Ankita Bhalu, Kalpesh Vilapara, Minaxi Maru, Manish Shah, International Letters of Chemistry, Physics and Astronomy 12 (2014) 51-55. 